\section{Case Reports in Neurology}

Case Rep Neurol 2020;12:137-142

DOI: 10.1159/000505967

Published online: December 14, 2020

(c) 2020 The Author(s)

Published by S. Karger AG, Basel

www.karger.com/crn

This article is licensed under the Creative Commons Attribution-NonCommercial 4.0 International License (CC BY-NC) (http://www.karger.com/Services/OpenAccessLicense). Usage and distribution for commercial purposes requires written permission.

\title{
Diagnosis and Management of Moyamoya Disease
}

\author{
Shinichiro Uchiyama ${ }^{a} \quad$ Masako Yamazaki $^{b} \quad$ Tatsuya Ishikawa $^{c}$ \\ Koji Yamaguchic Takakazu Kawamata ${ }^{c}$ \\ aClinical Research Center for Medicine, International University of Health and Welfare, \\ Center for Brain and Cerebral Vessels, Sanno Hospital and Sanno Medical Center, \\ Tokyo, Japan; bepartment of Neurology, Tokyo Women's Medical University School of \\ Medicine, Tokyo, Japan; 'Department of Neurosurgery, Tokyo Women's Medical \\ University School of Medicine, Tokyo, Japan
}

\section{Keywords}

Ischemic stroke $\cdot$ Hemorrhagic stroke $\cdot$ Bypass surgery

\section{Abstract}

Moyamoya disease is an uncommon vascular disease, which causes obstruction and stenosis of arteries of the circle of Willis, and preferentially affects children and young adults. This disease is seen across the world, but is more common in East Asia. It may cause hemorrhagic or ischemic stroke, or transient ischemic attack. If symptoms or cerebral blood flow become worse, revascularization surgery is recommended. We present 2 cases of moyamoya disease who underwent bypass surgery. We also discuss the epidemiology, pathology, genomics, and symptomatology as well as diagnosis, and management of moyamoya disease.

(C) 2020 The Author(s)

Published by S. Karger AG, Basel

\section{Introduction}

Moyamoya disease is a rare, progressive vascular disorder in which arteries of the circle of Willis becomes obstructed or stenosed, reducing blood flow to the brain [1-3]. Moyamoya disease is found all over the world, but it is more common in East Asian countries. There are

\begin{tabular}{ll}
\hline & Shinichiro Uchiyama \\
Sanno Medical Center \\
8-5-35 Akasaka \\
Minato-ku, Tokyo 10-8332 (Japan) \\
suchiyama@iuhw.ac.jp
\end{tabular}




\section{Case Reports in Neurology}

Case Rep Neurol 2020;12:137-142

DOI: 10.1159/000505967

(c) 2020 The Author(s). Published by S. Karger AG, Basel www.karger.com/crn

Uchiyama et al.: Diagnosis and Management of Moyamoya Disease

two peaks of onset in moyamoya disease $[2,4,5]$; one is in childhood and the other is in young adulthood. Moyamoya disease may cause transient ischemic attack (TIA), stroke, aneurysm, or bleeding in the brain $[2,5,6]$. If symptoms become worse or if tests show evidence of low blood flow, revascularization surgery is recommended. We present 2 cases of moyamoya disease; one had ischemic stroke and the other had hemorrhagic stroke, they both underwent bypass surgery.

\section{Case 1}

A 44-year-old male had repeated attacks of right hemiparesis after hyperventilation and exercise such as swimming since childhood. He visited a pediatric clinic, but no diagnosis was made, and did not have any further attack. Since 1 year ago, he had frequent tingling of the right upper extremity and muscle cramps of the right lower extremity. Thereafter, he had left hemiparesis after drinking alcohol. He visited a clinic, and was found to have bilateral internal carotid artery (ICA) occlusion and a watershed infarction in the right frontal lobe, and thus was diagnosed with moyamoya disease. He was referred to the Department of Neurosurgery of Tokyo Women's Medical University Hospital for the purpose of surgery. He had no particular medical history, but his daughter had moyamoya disease.

Upon neurological examination on admission, he had left hemiparesis; $2 / 5$ in the upper extremity and 4/5 in the lower extremity on manual muscle testing. Walking was possible with assistance of a cane. His brain MRI showed an infarction in the frontal watershed area (Fig. 1a). On brain MR angiography, the right ICA was poorly visualized, and the left ICA was obstructed, even though it had been previously treated with carotid artery stenting by a neurosurgeon at another hospital (Fig. 1b). The right conventional cerebral angiography showed complete occlusion of the right ICA distal to the bifurcation of the ophthalmic artery, and anastomosis from the ophthalmic artery to the contralateral anterior cerebral artery territory. There was no indirect anastomosis from the external carotid artery, and only flow from the posterior communicating artery to the right side. On the left conventional angiography, there was anastomosis from the left ascending pharyngeal artery but no natural indirect anastomosis from the middle meningeal artery. His single-photon emission computerized tomography (SPECT) showed extreme reduction of blood flow at rest (Fig. 1c) and steal phenomenon (Fig. 1d) in the right cerebral hemisphere.

The right superficial temporal artery (STA)-middle cerebral artery (MCA) double bypass surgery was performed. After the surgery, good patency of double bypass was confirmed (Fig. 1e). There was no recurrence of stroke thereafter. This was a case in whom diagnosis and surgical intervention were delayed despite frequent episodes. After the surgery, his motivation and activity remarkably improved.

\section{Case 2}

A 34-year-old male was transferred to the Emergency Department of Tokyo Women's Medical University because of sudden loss of consciousness. His brain CT showed ventricular hemorrhage (Fig. 2a) and acute hydrocephalus. Drainage of his bilateral lateral ventricles was performed. He was diagnosed with moyamoya disease by cerebral angiography after improvement of consciousness. He was planned to be treated with vascular reconstruction procedure after moving to a rehabilitation hospital. He had medical histories of syphilis and gout, but no particular family history. He had no residual neurological deficits.

On cerebral angiography, there was marked dangerous anastomosis via the left anterior choroidal artery and meningeal anastomosis from the left anterior cerebral artery, and no

\section{Karger'=}




\section{Case Reports in Neurology}

Case Rep Neurol 2020;12:137-142

DOI: 10.1159/000505967

(c) 2020 The Author(s). Published by S. Karger AG, Basel www.karger.com/crn

Uchiyama et al.: Diagnosis and Management of Moyamoya Disease

stenotic lesion of the posterior cerebral artery. His SPECT showed reduced cerebral blood flow (Fig. 2b) and cerebrovascular reactivity (Fig. 2c) in the left cerebral hemisphere.

He underwent the left STA-MCA double bypass surgery (Fig. 2d). Mild hyperperfusion occurred after the surgery but could be controlled with sedation, analgesia, and blood pressure lowering $[7,8]$. His cognitive function improved.

This was a typical case of hemorrhagic stroke with dangerous choroidal anastomosis on cerebral angiography [9]. Only direct bypass surgery is proven to be effective in patients with hemorrhagic type of moyamoya disease.

\section{Discussion}

Moyamoya disease is a rare, progressive vascular disorder in which arteries of the circle of Willis become obstructed or stenosed, reducing the blood flow to the brain [1,3]. Tiny blood vessels then develop at the base of the brain in an attempt to supply blood to the brain. The word "moyamoya" means "puff of smoke" in Japanese, a term describing the appearance of net-like tiny blood vessels.

Moyamoya disease is found all over the world, but it is more common in East Asian countries, especially Japan, Korea, and China, and in people of East Asian descent [4]. Female gender is more prevalent in Japanese and Korean patients [4,5]. There are two peaks of onset in moyamoya disease $[2,4,5]$; one is in childhood, and the other is in young adults. Ischemic stroke is dominant in children and hemorrhagic stroke is dominant in adults $[2,5,6]$.

In autopsy, intimal hyperplasia, atrophic media, and widening of the internal elastic lamina can be seen in affected arteries [2,5]. In 2011, A genome-wide association study identified $R N F 213$ as the first moyamoya disease gene in Japanese patients with familiar moyamoya disease [10]. In the same year, RNF213 was also identified as a susceptibility gene for not only Japanese but also Korean and Chinese populations [11].

Moyamoya disease may cause TIA, stroke, aneurysm, or bleeding in the brain $[2,5,6]$. It can also cause cognitive and developmental delays or disability. Cerebral angiography of moyamoya disease shows stenosis and occlusion of arteries of the circle of Willis with moyamoya vasculature as developed collateral circulation $[2,3,12]$. Flow void sign suggests moyamoya vasculature on MRI in bilateral basal ganglia $[13,14]$. Electroencephalography shows rebuild up of delta waves once hyperventilation is stopped, which is a typical finding in moyamoya disease $[2,11,15]$.

Medications are prescribed to reduce the risk of stroke or to control seizure [2]. Aspirin or other antiplatelet drugs are recommended to prevent strokes. Calcium channel blockers may relieve headaches. Anti-seizure medications should be prescribed if the patient has seizure disorder.

If symptoms become worse or if tests show evidence of low blood flow, revascularization surgery is recommended. Direct or indirect revascularization procedures, or a combination of both may be used. Indirect procedures include encephaloduroarteriosynangiosis or encephalomyosynangiosis $[2,12,16]$. In direct revascularization surgery, the scalp artery is sutured directly to a brain artery to immediately increase blood flow to the brain $[2,12,16]$. The Japan Adult Moyamoya (JAM) trial compared bilateral extracranial-intracranial direct bypass and conservative care in 80 patients with moyamoya disease with an age range of 18-65 years. Patients in the bypass surgery group at the primary endpoint experienced significantly less recurrent intracranial hemorrhage, completed stroke, or crescendo TIA, and also experienced

\section{Karger'=}




\section{Case Reports in Neurology}

\begin{tabular}{l|l}
\hline Case Rep Neurol 2020;12:137-142 \\
\hline DOI: 10.1159/000505967 & $\begin{array}{l}\text { @ 2020 The Author(s). Published by S. Karger AG, Basel } \\
\text { www.karger.com/crn }\end{array}$ \\
\hline
\end{tabular}

Uchiyama et al.: Diagnosis and Management of Moyamoya Disease

less recurrent bleeding related to death or severe disability at the secondary endpoint compared to the conservative care group [17].

\section{Statement of Ethics}

The 2 patients presented signed written informed consent forms.

\section{Conflict of Interest Statement}

The authors have no conflicts of interest to disclose for this report.

\section{Funding Sources}

The authors did not receive any funding to support this report.

\section{References}

1 Suzuki J, Takaku A. Cerebrovascular "moyamoya" disease. Disease showing abnormal net-like vessels in base of brain. Arch Neurol. 1969 Mar;20(3):288-99.

2 Research Committee on the Pathology and Treatment of Spontaneous Occlusion of the Circle of Willis Health Labour Sciences Research Grant for Research on Measures for Intractable Diseases. Guidelines for diagnosis and treatment of moyamoya disease (spontaneous occlusion of the circle of Willis). Neurol Med Chir (Tokyo). 2012;52(5):245-66.

3 Fujimura M, Tominaga T. Diagnosis of moyamoya disease: international standard and regional differences. Neurol Med Chir (Tokyo). 2015;55(3):189-93.

4 Kuroda S, Houkin K. Moyamoya disease: current concepts and future perspectives. Lancet Neurol. 2008 Nov;7(11):1056-66.

$5 \quad$ Kuriyama S, Kusaka Y, Fujimura M, Wakai K, Tamakoshi A, Hashimoto S, et al. Prevalence and clinicoepidemiological features of moyamoya disease in Japan: findings from a nationwide epidemiological survey. Stroke. 2008 Jan;39(1):42-7.

6 Hishikawa T, Sugiu K, Date I. Moyamoya disease: a review of clinical research. Acta Med Okayama. 2016 Aug;70(4):229-36.

7 Nomura S, Yamaguchi K, Ishikawa T, Kawashima A, Okada Y, Kawamata T. Factors of delayed hyperperfusion and the importance of repeated cerebral blood flow evaluation for hyperperfusion after direct bypass for moyamoya disease. World Neurosurg. 2018 Oct;118:e468-72.

8 Ishikawa T, Yamaguchi K, Kawashima A, Funatsu T, Eguchi S, Matsuoka G, et al. Predicting the occurrence of hemorrhagic cerebral hyperperfusion syndrome using regional cerebral blood flow after direct bypass surgery in patients with moyamoya disease. World Neurosurg. 2018 Nov;119:e750-6.

9 Funaki T, Takahashi JC, Yoshida K, Takagi Y, Fushimi Y, Kikuchi T, et al. Periventricular anastomosis in moyamoya disease: detecting fragile collateral vessels with MR angiography. J Neurosurg. 2016 Jun;124(6):1766-72.

10 Kamada F, Aoki Y, Narisawa A, Abe Y, Komatsuzaki S, Kikuchi A, et al. A genome-wide association study identifies RNF213 as the first Moyamoya disease gene. J Hum Genet. 2011 Jan;56(1):34-40.

11 Liu W, Morito D, Takashima S, Mineharu Y, Kobayashi H, Hitomi T, et al. Identification of RNF213 as a susceptibility gene for moyamoya disease and its possible role in vascular development. PLoS One. 2011;6(7):e22542.

12 Fukui M. Guidelines for the diagnosis and treatment of spontaneous occlusion of the circle of Willis ('moyamoya' disease). Research Committee on Spontaneous Occlusion of the Circle of Willis (Moyamoya Disease) of the Ministry of Health and Welfare, Japan. Clin Neurol Neurosurg. 1997 Oct;99 Suppl 2:S238-40.

13 Harada A, Fujii Y, Yoneoka Y, Takeuchi S, Tanaka R, Nakada T. High-field magnetic resonance imaging in patients with moyamoya disease. J Neurosurg. 2001 Feb;94(2):233-7. 


\section{Case Reports in Neurology}

\begin{tabular}{l|l}
\hline Case Rep Neurol 2020;12:137-142 \\
\hline DOI: 10.1159/000505967 & $\begin{array}{l}\text { @ 2020 The Author(s). Published by S. Karger AG, Basel } \\
\text { www.karger.com/crn }\end{array}$ \\
\hline
\end{tabular}

Uchiyama et al.: Diagnosis and Management of Moyamoya Disease

14 Kuroda S, Kamiyama H, Isobe M, Houkin K, Abe H, Mitsumori K. Cerebral hemodynamics and "re-build-up" phenomenon on electroencephalogram in children with moyamoya disease. Childs Nerv Syst. 1995 Apr;11(4):214-9.

15 Dlamini N, Goyal S, Jarosz J, Hampton T, Siddiqui A, Hughes E. Paroxysmal episodes, "re-build up" phenomenon and moyamoya disease. Epileptic Disord. 2009 Dec;11(4):324-8.

16 Kuroda S, Houkin K. Bypass surgery for moyamoya disease: concept and essence of sugical techniques. Neurol Med Chir (Tokyo). 2012;52(5):287-94.

17 Miyamoto S, Yoshimoto T, Hashimoto N, Okada Y, Tsuji I, Tominaga T, et al.; JAM Trial Investigators. Effects of extracranial-intracranial bypass for patients with hemorrhagic moyamoya disease: results of the Japan Adult Moyamoya Trial. Stroke. 2014 May;45(5):1415-21.
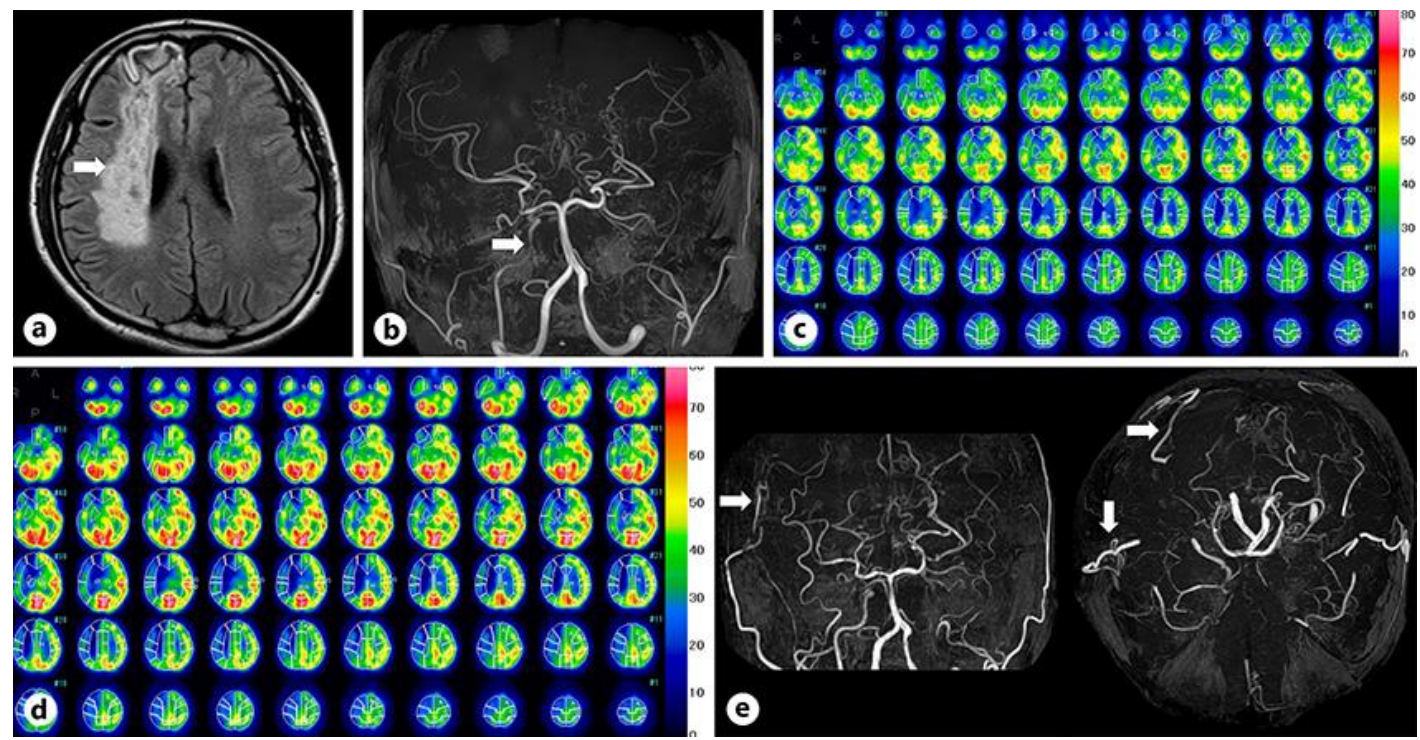

Fig. 1. Brain and vascular imaging in Case 1. a His brain MR fluid-attenuated inversion recovery image shows a watershed infarction in the right cerebral hemisphere (white arrow). b On MR angiography, the right ICA was poorly visualized (white arrow), and the left ICA was not visible. c His SPECT at rest shows extremely reduced blood flow in the right cerebral hemisphere (left side). d Steal phenomenon was induced by Diamox administration in the right cerebral hemisphere (left side). e Good patency was confirmed after the right STA-MCA double bypass surgery on magnetic resonance angiography (white arrows). 


\section{Case Reports in Neurology}

\begin{tabular}{l|l}
\hline Case Rep Neurol 2020;12:137-142 \\
\hline DOI: 10.1159/000505967 & $\begin{array}{l}\text { ( ) 2020 The Author(s). Published by S. Karger AG, Basel } \\
\text { www.karger.com/crn }\end{array}$ \\
\hline
\end{tabular}
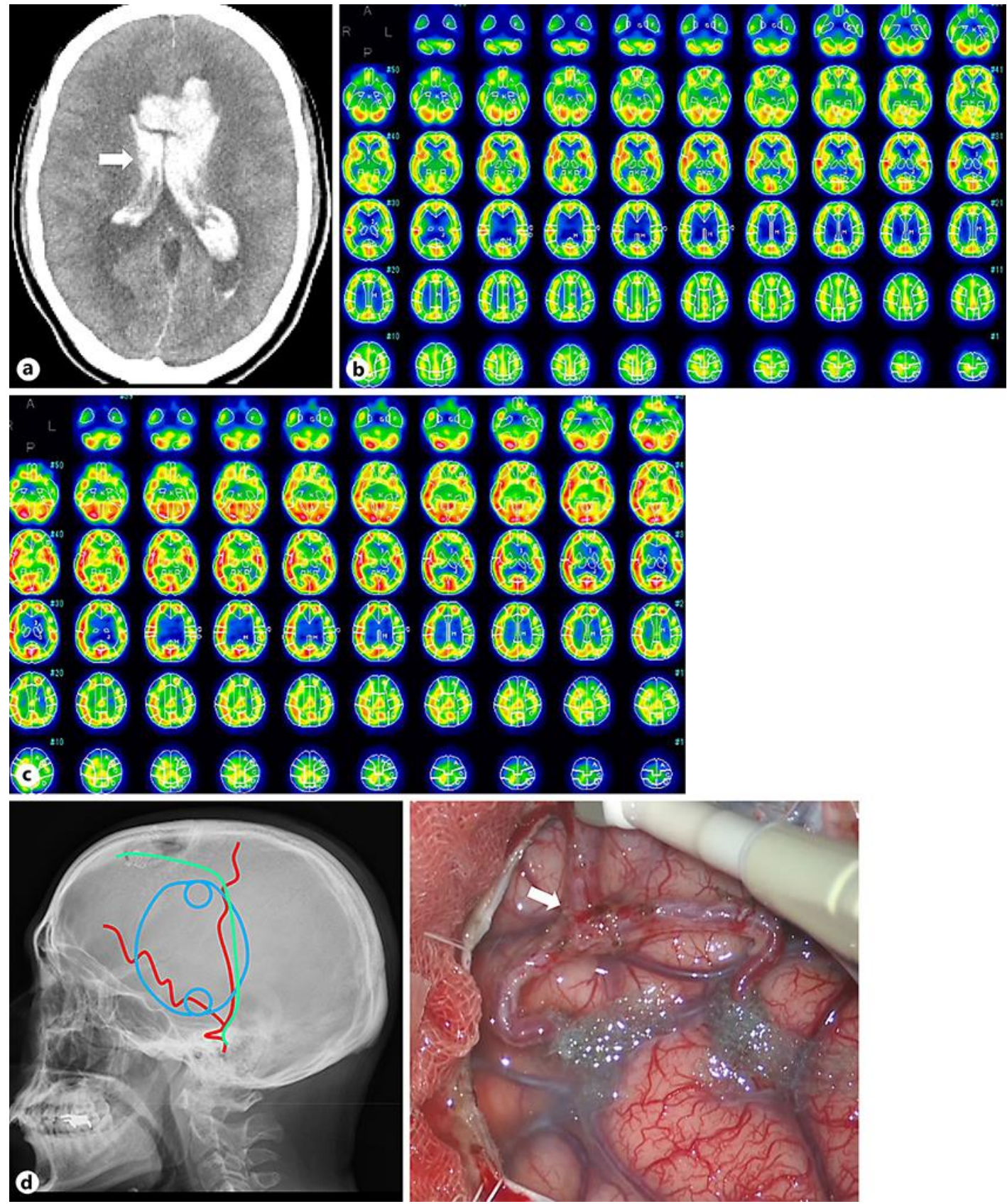

Fig. 2. Brain and vascular imaging, and pictures of bypass surgery in Case 2. a His brain CT shows ventricular hemorrhage (white arrow). b His SPECT showed reduced blood flow in the left temporal and parietal lobes at rest (right side). c Blood flow was greatly reduced in the left cerebral hemisphere by Diamox administration (right side). d STA-MCA double bypass surgery was performed (white arrow). 